\title{
GÉNERO Y PODER POLÍTICO EN LA Domus Augusta
}

\author{
Marco Alviz \\ Universidad Nacional de Educación a Distancia
}

Recibido: 09/03/2016 / Evaluado: 14/04/2016 / Aprobado: 14/04/2016

RESUMEN: En este artículo pretendemos analizar el poder político de las mujeres de la Domus Augusta a nivel institucional. Una serie de elementos presentes en las fuentes historiográficas nos indican hasta qué punto ejercieron su influencia sobre las fuerzas que estaban investidas con el poder político de manera constitucional. No obstante, la elevada carga ideológica de la Historia de las Mujeres ha convertido muchas veces dicha influencia en un cargo público institucionalizado. Así, tratamos de depurar las connotaciones ideológicas para, una vez definido el poder político en el Principado, analizar respecto al mismo la naturaleza del que verdaderamente ejercieron las damas imperiales.

Palabras clave: historia de género, historia institucional, poder político, Principado, Domus Augusta.

ABSTRACT: In this paper, we aim to analyze the institucionally-based political power of the Domus Augusta women. Ancient sources show us to what extent these women influenced the invested forces with constitutional political powers. However, the ideologically-charged History of Women has, several times, taken this influence to such extent as to speak of a constitutionally arranged official background. This study tries accurately to determine ideological implications and compare the political power of the Principate with those which the women of the imperial court really exercised.

Keywords: Gender History, Institutional History, political power, Principate, Domus Augusta. 
$\mathrm{E}^{n}$ n este artículo pretendemos explorar la cuestión del posible poder político ejercido a nivel institucional por el género femenino de la Domus imperial a lo largo del Principado. Destacan sus periodos inicial y final porque se trata de las etapas en que las transformaciones a ellas asociadas hacen patente ese acercamiento de las mujeres del entorno palatino a posiciones de cierto poder. En esta línea, observaremos cómo algunos autores modernos han interpretado dicho fenómeno bien a modo de la institucionalización de su estatus, bien como equiparación de sus poderes respecto a los del princeps. Enfoques a través de los cuales se extralimita el poder de las consortes imperiales hasta el punto de concederles trascendencia constitucional $-i$. e., institucionalizan su función pública-. ${ }^{1}$

Si bien parece cierto que existió cierta presión por parte del género femenino en la forma de las mujeres de la Domus imperatoria contra el muro que suponía su incapacidad jurídica para ejercer cargos públicos, no es óbice para que desde una Historia de las Mujeres ideologizada en exceso se trate incluso de convertirlas en partícipes del gobierno de la res publica.

El concepto de «género» se originó en las décadas de los setenta y ochenta del siglo pasado -de la mano de autoras como Pomeroy-2 ${ }^{2}$ en una evolución de la Historia de las Mujeres surgida a raíz de los movimientos feministas precedentes. Pero, más allá del carácter transgresor de sus inicios y su fuerte carga ideológica, lo debemos comprender en la actualidad como el modo de referirse a las mujeres en el ámbito académico.

Conviene asimismo precisar el carácter del término Domus Augusta. El mismo comprendió a lo largo del Principado a la familia imperial. Aparece por primera vez en el documento oficial de la Tabula Siarensis, una copia del senatus consultum del año $19 \mathrm{~d}$. C. en honor a la memoria de Germánico, hijo adoptivo de Tiberio; ${ }^{3}$ si bien la primera referencia se remontaría al año 15 d. C. en un conjunto estatuario dirigido al divino Augusto y a su casa. En el texto mandado redactar por el Senado se muestra la jerarquía interna de la familia imperial dando a entender su legitimidad por el vínculo biológico. ${ }^{4}$ Tenemos, entonces, una Domus Augusta entendida como una entidad familiar colectiva superior ${ }^{5}$ a la cual se la deben rendir los honores correspondientes en virtud de su trascendencia como continuadora del poder imperial. En ella, las mujeres tenían un rol como reforzadoras de los engranajes hereditarios a través de sus matrimonios, i.e., como instrumentos de legitimación dinástica ${ }^{6}$ No hemos de olvidar la naturaleza sacra de la que participaba la familia

1. Richard A. Bauman: Women and Politics in Ancient Rome, Routledge, Londres, 1992, 6.

2. Cf. Sarah B. Pomeroy: «Selected Bibliography on Women in Antiquity», Arethusa, 6, 1973, 125-162; Ibid.: Goddesses, Whores, Wives, and Slaves: Women in Classical Antiquity, Schocken, Nueva York, 1975.

3. Mireille Corbier: Donner à voir, donner à lire. Mémoire et communication dans la Rome ancienne, CNRs Éditions, París, 2006, 188.

4. Ibid., Donner à voir, 190.

5. Ibid., Donner à voir, 193-194.

6. Ibid., Donner à voir, 191. 
imperial al asociarse a la divinidad de su fundador -divina domus-. Así, los distintos ordines demuestran su devoción - pietas, compuesta por veneratio y caritas - hacia la misma de idéntica manera que el ejército su lealtad -fides, como custodia del poder imperial-, lo que encontramos en el senadoconsulto bajo la siguiente fórmula: fidem pietam(que) domui Aug(ustae).

\section{PODER POLÍtTICO EN EL PRINCIPADO}

El poder político en una sociedad patriarcal y denotadamente machista como la del Imperio romano -básicamente porque se trataba de una monarquía militar- radicaba en la condición jurídica, es decir, derivaba directamente del estatus de ciudadano - ciues-. Este tan solo lo ostentaban los hombres, cabezas de familia -pater familias-, las cuales funcionaban como corporaciones que estructuraban la sociedad. No es que se les negase explícitamente dicha condición a las mujeres, sino que más bien en las familias existían distintos roles asociados a cada uno de sus miembros: los hombres se encargarían de la defensa y gobierno del Imperio, y las mujeres, desde casa, naturalmente, repondrían las bajas. Con todo, debemos comprender que el poder político que el género femenino podía llegar a ostentar en este periodo de la historia iba irremediablemente de la mano del hombre junto al que se asociaba, en nuestro caso, el propio emperador.

Así, la cuestión que debemos tratar en primer lugar no es otra sino la definición de las instituciones que investían de poder político en el Principado, i. e., cuáles eran los pilares que sustentaban el nuevo régimen cuasimonárquico instaurado por Augusto.

En el año 27 a. C. le fue concedido a Octaviano el título de Augustus y en el 23 a. C. se le otorgó la tribunicia potestas -no en vano ostentaba ya desde el 36 a. C. la sacrosanctitas tribunicia, al igual que lo hiciera su padre adoptivo- junto con el imperium proconsulare maius -como en el 43 a. C. los republicanos Bruto y Casio- et infinitum. Finalmente, en el 12 a. C., una vez fallecido el antiguo triunviro Lépido ( $R g d A$ 10.2), se hizo con el cargo vitalicio de Pontifex Maximus, la máxima autoridad religiosa.

La comunidad científica admite, en general, con Kienast «dass das imperium proconsulare (maius) und die tribunicia potestas, die beiden hauptsächlichsten Instrumente, mit denen Augustus seit 23 regierte, keine Ämter, sondern nur von Ämtern entlehnte Gewalten waren». ${ }^{7}$ Estamos ante las palancas del poder político del Principado -atribuciones institucionales gracias a las cuales se cimentará su nueva forma de gobierno-, las cuales no hemos de entender como las propias magistraturas, sino tan solo el poder que

7. Dietmar Kienast: Augustus: Prinzeps und Monarch, Wissenschaftliche Buchgesellschaft, Darmstadt, 1999, 107. 
estas comprendían. ${ }^{8}$ Se trata, en definitiva, de conceptos de vital importancia que es preciso que detallemos su significado cuando menos someramente.

El imperium es una de las más antiguas instituciones romanas, existía ya en la primitiva Monarquía con atribuciones político-religiosas. En la República eran investidos con el mismo por el pueblo romano los altos magistrados y conllevaba una implicación militar que desde el siglo I a. C. adquiere mayor significado debido a su relevancia en el terreno político, y que alcanza su punto álgido con Julio César. Los emperadores serían investidos mediante un acto formal por parte del Senado en el conocido como dies imperii; será unipersonal y no contará con limitaciones en el espacio gracias a los decisivos añadidos de maius - por encima de todos los magistrados cum imperio- et infinitum - no supeditado al límite del pomerium-. ${ }^{9}$ Así pues, desde su originaria acepción de salutación como imperator por las legiones tras un éxito militar, pasó a ser asumido como cognomen y, finalmente, con Augusto, como praenomen, derivando hacia nuestra voz «emperador» que integra todos sus valores. ${ }^{10}$

La potestas era la capacidad otorgada por el pueblo de Roma de ejercer determinados poderes administrativos civiles y judiciales de los magistrados menores. Por su parte, la tribunicia potestas, el poder civil de los magistrados plebeyos: los tribunos de la plebe. Augusto, ad tuendam plebem (Tac. Ann. 1.2), se la atribuyó en el año 23 a. C. Le confería la prerrogativa de inviolabilidad sacrosanta además de poder legislativo y judicial sobresaliendo el poder de intercessio o veto a las decisiones del Senado. Igualmente, los años de su reinado se contarían por medio de este cargo, que a su vez utilizaría para nombrar a sus sucesores o adjuntos al poder.

El poder del Imperio romano se consolidó, así, a través de estas instituciones rodeadas de un aura de auctoritas que lo legitimaba-auctoritas principis-. Una auctoritas que representó en el periodo republicano la «justificación constitucional soberana del Senado»-«verfassungsrechtliche Souveränitätsposition des Senats»-, y en el imperial la de los césares - «verfassungsrechtliche Souveränitätsposition des Kaisers»-, ${ }^{11}$ instante en el que "devient l'une des composantes du pouvoir impèriale». ${ }^{12}$ Queda así levantado el edificio del poder imperial basado en la gracia de la persona del emperador. El cual enraizará de tal manera que perdurará prácticamente inmutable por lo menos hasta el siglo iII d. C.

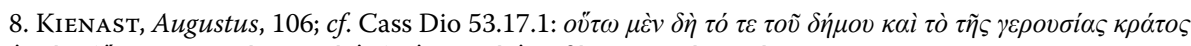

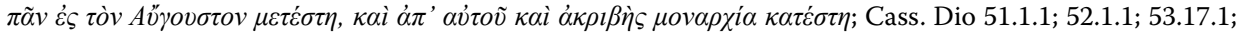
$\operatorname{RgdA} 34.1$.

9. Comprendía, en definitiva: el mando de los ejércitos, el ius edicendi o derecho de dirigirse al pueblo y dictar ordenanzas de validez universal, la iurisdictio o facultad de administrar justicia civil y criminal, el ius agendi cum patribus y cum populo -derecho de convocar al senado y al pueblo- así como la coercitio o poder disciplinario. Además, continuaban poseyendo imperium los cónsules, los pretores y los procónsules de las provincias públicas, así como los asociados a la sucesión por el propio princeps.

10. Barbara M. Levick: Julia Domna: Syrian Empress, Routledge, Londres / Nueva York, 2007, 82.

11. Der Neue Pauly, 2, 265.

12. Jean Leclant: Dictionnaire de l’Antiquité, Anabases, París, 2005, 277. 


\section{LA DiNASTía JULIO-CLAUDia}

La primera ocasión en que se muestra el debate en la historiografía moderna sobre la constitucionalidad del poder de una mujer de la corte imperial es por el hecho de la sacrosanctitas tribunicia otorgada por Octaviano, a través del senado, a su hermana Octavia y a su esposa Livia en

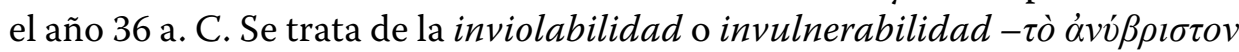
(Cass. Dio 49.38.1), «Unverletzlichkeit» ${ }^{13}-$ de los tribunos de la plebe, junto a la que se incluyeron a su vez los privilegios de la liberación de tutela y, tal vez a modo de ratificación de la concesión, ${ }^{14}$ de la erección de estatuas. ${ }^{15}$ Una dispensa que no tiene precedentes y que Bauman ${ }^{16}$ define como análoga a la de un cargo público, subrayando la idea de que no resultaba el cargo en sí mismo. Por su parte, Hidalgo de la Vega ya vislumbra en la misma lo que más tarde dará como un hecho, a saber, el comienzo de la institucionalización del poder de Livia. ${ }^{17}$ No obstante, si ahondamos en el contexto histórico que rodea la concesión -disensiones previas al definitivo enfrentamiento de Accio- comprenderemos que el eje de la acción es la hermana de Octaviano, ${ }^{18}$ a la que trataba de proteger de las injurias de su esposo, el triunviro Marco Antonio, en forma de infidelidad con Cleopatra. Además, obtendría así respaldo legal para iniciar las operaciones contra Antonio. Un marco, en definitiva, de propaganda de guerra. ${ }^{19}$

Otra cuestión que emerge como argumento para otorgarle a Livia un supuesto protagonismo de cariz político es como consejera y confidente de Augusto y de Tiberio. Las fuentes nos ofrecen variados ejemplos en los que nos muestran a una consorte que acompañaba al princeps en sus viajes ${ }^{20} \mathrm{y}$ que era consultada sobre asuntos de Estado ${ }^{21}$ o que intercambia cartas con

13. Realencyclopädie der classischen Altertumswissenschaft $(R E)$ 25.2, 1687.

14. Anthony A. Barrett: Livia: First Lady of Imperial Rome, Yale University Press, New Haven / Londres, 2002, 138.

15. Es Casio Dión (49.38.1) la única fuente en la que encontramos la noticia de esta concesión gracias a la cual ambas allegadas a la figura de Octaviano no podrían ser injuriadas ni de palabra ni de obra - $\grave{o} \mu \dot{\eta} \tau \varepsilon$

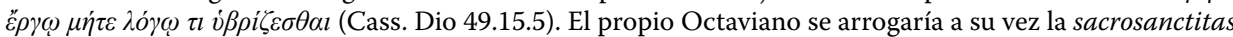
tribunicia el año anterior (cf. App. B Civ. 5.132, donde no habla de dicho atributo sino, erróneamente, de la propia magistratura plebeya) siguiendo a su padre adoptivo Julio César, el cual la habría recibido en 44 a. C.

16. BAUMAN, Women and politics, $94, \mathrm{n} .^{\circ} 12$.

17. MARÍA José HidAlgo DE LA VEGA: Las emperatrices romanas: sueños de púrpura y poder oculto, Ediciones Universidad de Salamanca, Salamanca, 2012, 35.

18. BARRetT, Livia: First Lady, 31-32, 136-137.

19. JASPer Burns: Great Women of Imperial Rome, Mothers and Wives of the Caesars, Routledge, Nueva York, 2007, 9.

20. Sobre el probable acompañamiento en la campaña de Hispania (27-24 a. C.): Burns, Great Women, 10. Sobre la práctica seguridad del de la campaña al este (22-19 a. C.): Bauman, Women and politics, 127. Sobre el rechazo de ciertas factiones del senado al hecho de que los legados acudieran a las campañas acompañados de sus mujeres: Tac. Ann. 3.33-34.

21. Algo que debiéramos enmarcar en el ámbito informal que Augusto concedería, intra cubiculum, a su esposa y a su hermana (BArretr, Livia: First Lady, 147). Es más, Suetonio (Aug. 40.3) nos expone un ejemplo de negativa a una petición de Livia en cuanto a la concesión del derecho de ciudadanía a un tributario galo. 
reyes bárbaros. ${ }^{22}$ Así, autores como Barrett o Crook afirman que no caben dudas de que Livia influyera en algunas de las políticas de Augusto. ${ }^{23}$ Pero este hecho no debe conducirnos a extralimitar el matiz «político» de su intervención e insertarlo en el ámbito institucional.

Un tópico que suele salir a la luz también en el caso de Livia -heredero de la tradición tacitea-, es el de los ardides de la consorte imperial para llevar a la púrpura a su hijo Tiberio. En efecto, el papel de Livia en la sucesión de Augusto se muestra distorsionado por una tradición que involucra continuamente su mano en la desaparición de los sucesivos candidatos. Por el contrario, la investigación moderna no lo acepta por falta de pruebas verdaderamente fiables, ${ }^{24}$ así como por la evidente falta de imparcialidad de las fuentes.

Un momento fundamental para comprender el rol de las mujeres de la familia principis se produjo a la muerte de Augusto. Y es que por disposición testamentaria Livia pasó a formar parte de la gens Iulia y su fórmula onomástica se transformó de manera que desde este momento sería conocida como Iulia Augusta. ${ }^{25}$ Técnicamente, Livia se convertía en hija de Augusto y hermana de Tiberio. Intrincado, pero único proceder para integrarla en la familia Julia. Una dispensa sin precedentes que, por un lado, fortalecía el derecho sobre la nueva posición de Tiberio haciéndole descendiente de ambos linajes de la dinastía ${ }^{26}$ y, por el otro, incluía la novedad del nomen de Augusta. Una novedad que confunde en ocasiones a los investigadores a la hora de su correcta interpretación. Así, es necesario recalcar que no podemos en ningún caso hablar de corregencia - «Mitregentschaft», como sugiriera Mommsen-, ${ }^{27}$ así como resulta demasiado arriesgado afirmar que su «significado modelado sobre el de Augusto, era el de "emperatriz"»». ${ }^{28}$ Para Barrett se trataría de una forma cuasi legal o cuasi constitucional de estatus en forma de título honorífico, el cual no será usado de manera homogénea por los sucesores de la 136.

22. Cf, Tac. Ann. 2.41.2; Suet. Tib. 37.4; Barrett, Livia: First Lady, 81; Bauman, Women and politics,

23. Barrett, Livia: First Lady, 133; John A. CrooK: «Augustus: power, authority, achievement», en Bowman, A. K.; Champlin, E.; Lintott, A. (eds.): The Cambridge Ancient History 10, Cambridge University Press, Cambridge, 2001, 129.

24. Burns, Great Women, 14; sobre el manido recurso del veneno del que tanto uso hacen algunos autores clásicos como arma de las mujeres: BARRETT, Livia: First Lady, xi, 112.

25. Tac. Ann. 1.8.1: Livia in familiam Iuliam nomenque Augustum adumebatur; Suet. Aug. 101.2: Heredes instituit primos: Tiberium (...), Liviam (...), quos et ferre nomen suum iussit; Cass. Dio 56.46.1: $\tau \grave{\eta} v$

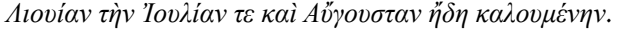

26. Barrett, Livia: First Lady, 151; Bauman, Women and politics, 131; Hidalgo de la Vega, Las emperatrices, 65.

27. RE 13.1, 916; cf. BAUMAN, Women and politics, 131.

28. Hidalgo de la Vega, Las emperatrices, 32. 
dinastía Julio-Claudia; ${ }^{29}$ desde Domiciano se convertirá en el título regular de la esposa del prínceps. ${ }^{30}$

Iulia Augusta murió en 29 d. C. No obstante, su divinización se hará esperar trece años hasta que Claudio la declarara oficialmente Diva Augusta en la búsqueda de legitimidad política para su precipitada ascensión. ${ }^{31} Y$ es que este se había apropiado del nombre de Caesar, el cual no había recibido ni por nacimiento ni por adopción. ${ }^{32}$ Por tanto, primero, como flaminica de Augusto - que para Hidalgo de la Vega ${ }^{33}$ supone un canal alternativo en la búsqueda para institucionalizar su poder-, es responsable del comienzo y desarrollo del culto imperial masculino; ${ }^{34}$ tras su deificación, podemos decir que también del femenino.

Son dos los acontecimientos, hacia el ocaso de la dinastía Julio-Claudia, en los que de nuevo se cuestiona el poder político institucional de una mujer de la Domus Augusta. Y en ambos el sujeto es Agripina la Menor. El primero guarda relación con el lugar de su nacimiento: el oppidum renano de Ara Ubiorum. La afección recíproca entre aquella y el asentamiento bárbaro puede relacionarse con los avatares de sus familiares en la región, por cuyas victorias obtuvieron el afamado cognomen de Germanicus. ${ }^{35}$ La fundación de la Colonia Claudia Ara Agrippinensium ${ }^{36}$ tuvo lugar en el año 50 d. C., momento en el que Agripina ya había conseguido anteponer a su hijo Nerón como heredero sobre el de su esposo y tío Claudio -Británico-, ante lo cual el Senado le otorgó el título de Augusta. En apenas dos años desde su matrimonio el estatus de Agripina había ascendido hasta la cúspide de poder que el derecho romano

29. Sin ir más lejos, en la dinastía Julio-Claudia, Calígula concedería el título a su abuela Antonia (Suet. Cal. 15.2; Cass. Dio 59.3-4), quien no haría uso del mismo (Suet. Claud. 11.2); Claudio se lo otorgará de nuevo de manera póstuma, no obstante, no hará lo propio con su esposa Mesalina rechazando la oferta del Senado al no considerarlo correcto estando en vida aquella; algo que, por el contrario sí haría Agripina la Menor en 50 d. C. (Tac. Ann. 12.26.1; Cass. Dio 60.33.2a) pasando a denominarse oficialmente Iulia Augusta Agrippina y será también la primera en aparecer en una misma moneda que el emperador (RIC ${ }^{2}$ Claudius $80-81 ; 717 ; 719)$. Su ejemplo lo tomará Nerón con su esposa Popea al dar a luz a su hija, también nombrada Augusta (Tac. Ann. 15.23).

30. BARRETt, Livia: First Lady, 148, 151, 323; KARL CHRIST: Geschichte der römischen Kaiserzeit, C.H. Beck, Múnich, 2009 (1. ${ }^{\text {a }}$ ed. 1988), 429; cf. Tac. Hist. 2.89.2.

31. Óbito de Iulia Augusta: Tac. Ann. 5.1; Cass. Dio 58.2.1; proclamación como Diva Augusta: Cass. Dio 60.5.2; Suet. Claud. 11.2; CIL VIII.6987, X.1413.

32. Bauman, Women and politics, 166; Rosa Cid López: «Livia versus diva Augusta. La mujer del príncipe y el culto imperial», ARYS, 1, 1998, 152.

33. Hidalgo de la Vega, Las emperatrices, 34.

34. Cf. María Dolores Mirón Pérez: Mujeres, religión y poder: el culto imperial en el occidente Mediterráneo, Universidad de Granada, Granada, 1996, 135-217.

35. Sobre la tribu germana de los Ubii: RE 8A.1, 532-533; Caes. B Gall. 4.1-3. Sobre el traslado del oppidum Ubiorum a la otra orilla del Rin: Strabo 4.3.4; Tac. Ann. 12.27, Germ. 28. Sobre el activo papel de Agripina la Mayor - «invaluable asset to Germanicus»- en la campaña germana: ANTHONy A. BARRETT: Agrippina. Sister of Caligula, Wife of Claudius, Mother of Nero, Yale University Press, New Haven / Londres, 1996, 28, 114.

36. Werner ECK: Köln in römischer Zeit, Greven, Colonia, 2004, 127-132; cf. RE 8A.1, 535-540. 
permitía al género femenino. ${ }^{37}$ No tardó el princeps en aceptar la petición de Agripina de conceder a su lugar de nacimiento del limes renano el cambio de estatus de ciudad peregrina a colonia (Tac. Ann.12.27.1-2). Tácito relaciona directamente la fundación con los deseos de Agripina de aumentar su posición de poder fuera de la Urbs, lo que Eck considera «sehr wohl möglich, vielleicht sogar wahrscheinlich $»^{38}$ y cuyo nombre de Agrippinensium deja claro quien había sido «die treibende Kraft» ${ }^{39}$ de la dispensa. Una «fuerza motriz» que Barrett compara en términos de paridad a la hora de disponer la concesión con Claudio - con quien, afirma, trabaja «in partnership $»^{40}-$, lo que podríamos matizar pues da a entender que Agripina comparte la actuación políticoadministrativa de su esposo, algo inviable en términos legales pues él, y solo él, era el princeps. ${ }^{41}$ En definitiva, observamos a una Agripina con un papel preponderante en la fundación de la colonia, pero siempre entendido desde su rol femenino, i.e. nunca como sujeto de la acción sino más bien como impulsora intelectual. ${ }^{42}$ La filiación que adquieren los ubios, desde entonces orgullosos de ser llamados Agrippinenses, ${ }^{43}$ mantendrá el paso de las generaciones en lo que se convirtió el monumento a su persona más duradero, el cual trascendió a su violenta muerte.

El segundo es la redacción y publicación de los Commentarii Agrippinae, lo que la convierte probablemente en la primera mujer en publicar en prosa latina. ${ }^{44} \mathrm{Si}$ bien no se corresponde con una institución política, destaca por el

37. Así se mostraba públicamente como observamos en la imagen que ofrece Plinio (HN 33.63), testigo presencial de los hechos, cuando la describe en los juegos del lago Fucino vistiendo una túnica militar en oro - paludamento aureo-, lo que Bauman (Women and politics, 183) describe como «an attempt to graze the fringes of imperium».

38. Еск, Köln, 133. El princeps vería con buenos ojos la propuesta en aras de «die Rheinfront zu stärken und ein starkes Rekrutierungsgebiet für die Rheinischen Legionen zu schaffen» (ibid., Köln, 133).

39. Ibid., Köln, 134.

40. BARrett, Agrippina, 115.

41. Además, Agripina podría haber actuado del mismo modo que Claudio en el caso del otorgamiento del sobrenombre de Claudia a su lugar de nacimiento de Lugdunum, en la Galia Narbonense, la cual ya por orden de Julio César era colonia romana y a la que también concedió el ius Italicum. Tampoco descarta una posible iniciativa de la propia ciudad y de unos dirigentes conocedores de los mecanismos romanos que, atentos a los sucesos de Roma, se hicieran presentes en la boda de Agripina, lo cual tal vez recordase a aquella su cercana relación con la misma y surgiese la idea de la fundación (ECK, Köln, 137).

42. En este sentido, en el $O C D$ («Colonia Agrippinensis») se pone como sujeto de la acción a Claudio, que lo llevaría a cabo en honor a su mujer, sin mencionarla, por el contrario, en ningún momento como impulsora de la misma. De forma opuesta, BARRETt, Agrippina, 114-115, deja de lado los honores simbólicos para subrayar que tomaría más bien caracteres de patrocinio al modo de la vieja relación patrón-cliente que ya había producido con ciudades como Ilium -Troya, con César y Augusto- y Epidauro -con Tiberio-. En la misma línea, Susan Wood: Imperial Women. A Study on Public Image (40 BC-AD 68), Leiden / Boston / Colonia, 2001, 250-251, también describe a los ubios como clientes de Agripina de la misma manera que Livia había contado con ellos en provincias. Cf. BAuman, Women and politics, 182, «she arranged for the foundation».

43. De hecho, en la onomástica de cualquier ciues Romanus de la colonia llevaría los tria nomina correspondientes con el añadido de Agrippinensis. Nombre que eclipsó la referencia al nombre indígena de la ciudad y de sus habitantes.

44. Emily Ann Hemerlijk: Matrona Docta: Educated Women in the Roman Elite from Cornelia to Julia Domna, Routledge, Londres / Nueva York, 1999, 185; destaca como «remarkable exception» el hecho de que suponga el único tratado en prosa conocido escrito por una mujer, de las que sí conocemos que escribían cartas. El género epistolar, ya para asuntos políticos como domésticos, era empleado por ambos sexos de 
hecho de que las motivaciones fundamentales que llevaron a su redacción sí tomaron un cariz político en tanto en cuanto parecen destinados a ensalzar su figura y la de su familia. Una familia, no hemos de olvidar, que desciende directamente del fundador del Principado. Es necesario precisar que se trata de un subgénero literario de estilo sencillo nacido de los apuntes de los magistrados que gobernaban las provincias sobre los asuntos militares y civiles que se encargaban y que adquirió carácter autobiográfico. ${ }^{45}$ Son tres las únicas fuentes en las que encontramos referencias a la obra de nuestra protagonista. ${ }^{46}$ Ya fuera redactada durante el reinado de Claudio como propaganda contra Mesalina; una vez casada con aquel como propaganda de su hijo y de su ascendencia frente a Británico; o bien en el periodo de ostracismo en el que se vio envuelta desde el año 55, su objetivo se define de talante eminentemente político.

\section{LA DINASTÍA ANTONINA}

Con la dinastía Antonina resulta communis opinio que el Imperio romano alcanzó su apogeo de poder, concretamente en el reinado de Trajano. Y la cuestión sucesoria adquirió desde el mismo Nerva el cariz con que la dotó la adoptio optimi, "claramente una ficción de la sucesión hereditaria». ${ }^{47} \mathrm{La}$ adopción era el mecanismo tradicional de actuación romano cuando no existía un heredero legítimo directo, y en este momento las mujeres de la dinastía consolidaron su papel de legitimadoras.

A Pompeia Plotina, esposa de Trajano, se la ha llegado a asociar a Livia debido a las analogías entre sus roles como consortes, ${ }^{48}$ sobresaliendo el momento sucesorio. Si bien es cierto que el exitoso reinado del italicense -al igual que el de Augusto- provocó una historiografía favorable que lo construyó en consonancia a la virtus de su persona y, por extensión, también a

propia mano -sobre todo cuando iban dirigidas a amigos íntimos o se trataba de asuntos confidenciales-o valiéndose de escribas (ibid., Matrona Docta, 188-208).

45. Hemerlijk, Matrona Docta, 186-188. Tal vez Agripina se inspirara en las obras de sus parientes Augusto -De vita sua en trece libros (Suet. Aug. 85)-, Tiberio (Comentarius de vita sua escrito summatim breviterque (Suet. Tib. 61.1) - y el propio Claudio -De vita sua en ocho libros (Suet. Claud 41.3)-.

46. Tac. Ann. 4.53.2; Plin. HN 7.17; Cass. Dio 60.33.1; cf. BArret t, Agrippina, 198-199; Alessandra LAzZeretti: «Reflessioni sull'opera autobiografica di Agrippina Minore», Género, poder y conflicto, Studia histórica, Historia Antigua, 18, 2000, 177-190; Ronald Syme: Tacitus, Oxford University Press, Oxford, 1989 (1. ${ }^{a}$ ed. 1958), 278, «it was not a trivial matter».

47. Hidalgo de la Vega, Las emperatrices, 100; Michael Griffin: «Nerva to Hadrian», en BowmAN, A. K.; Garnsey, P.; Rathbone, D. (eds.): The Cambridge Ancient History 12, Cambridge University Press, Cambridge, 2000, 94, 96-98; WERnER ECK: «An Emperor is Made: Senatorial Politics and Trajan's Adoption by Nerva in 97», en ClARK, G.; Rajak, T. (eds.): Philosophy and Power in the Graco-Roman World, Oxford University Press, Oxford, 211-228.

48. Su oscura familia (RE s. V: 2293-2298) procedía del ordo ecuestre de la ciudad de Nemausus -la moderna Nimes-, en la Galia Narbonense (sHA Hadr. 12.2). Ejemplo del ascenso de algunas familias provinciales del siglo I-II hasta el senado (HIDALGO DE LA VEGA, Las emperatrices, 104). Sobre las analogías: epíteto de Burns, Great Women, 107: «the new Livia»; consejos intra cubiculum: e.g. Plin. Ep. 42.21; en campañas militares: Burns, Great Women, 115, Hidalgo DE LA VegA, Las emperatrices, 106-107. 
la de su esposa -sanctissima femina (Plin. Ep. 9.28.1; cf. Plin. Pan. 83.1-3, 5-8; 84.1)..$^{49}$ Destaca el relato (Plin. Pan. 84.6-8) sobre el rechazo inicial por parte de Plotina y Ulpia Marciana del título de Augusta que les ofrecía el Senado imitando la actitud del propio Trajano hacia el de pater patriae - una vez lo aceptó, las mujeres hicieron lo propio en $105 .{ }^{50}$ Hidalgo de la Vega establece una correspondencia entre el rol de Padre de la Patria de Trajano y el de Augusta de Plotina -entendido en este caso al modo de mater patriae- en la medida en que eran comprendidos por el Senado y el pueblo romano desde el momento de su acceso a la púrpura. ${ }^{51}$ Ambos se convertían, en definitiva, en los parentes patriae y así se reflejaría a través de la iconografía y de la onomástica una vez asumían los títulos legítimamente.

La sucesión de Adriano -hijo de un primo de Trajano- fue conocida por el Senado a través de una carta de un princeps enfermo que así lo disponía y que llevaba, para desconcierto de la curia, la firma de Plotina (Cass. Dio 68.33, 69.1.4). De esta manera se generaron historias infames y conspirativas desde las facciones senatoriales contrarias al nombramiento. Sin embargo, sabemos que la consorte imperial había asumido sus cuidados desde joven, parece que promovió su matrimonio con la sobrina-nieta del princeps, Sabina, ${ }^{52}$ y que apoyó su carrera política. Con todo, no debemos llegar al equívoco de juzgarla con el papel decisorio de la sucesión, algo que solo correspondía al emperador y de quien no parece haber dudas de que tenía clara su elección. ${ }^{53}$

La legitimación dinástica como uno de los principales roles femeninos -si no el principal- tiene su continuidad de la mano de Faustina la Mayor y, su hija, Faustina la Menor. Y es que, en palabras de Haensch, «jedes politische System bemüht sich um Stabilität und Kontinuität». ${ }^{54}$ La primera tan solo disfrutó del título de Augusta dos años -desde que su esposo, Antonino Pío, alcanzó la púrpura-, pues falleció tempranamente en 140, tras lo cual fue inmediatamente divinizada. No obstante, le dio tiempo a concertar el matrimonio de su hija

49. Este hecho lo refleja a la perfección la frase que Casio Dión (68.5.5) pone en su boca en el momento en que pisó el Palatino por primera vez: entro a este lugar como el tipo de mujer que me gustaría ser cuando lo

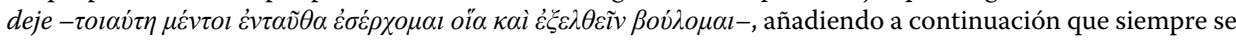
mantuvo firme en su cometido. Por su parte, Plinio la dibujó como modelo a seguir a través de su fidelidad, castidad y modestia; en este sentido parece que una de sus obras arquitectónicas que embelleció Roma fue el conocido como Ara Pudicitia. La pudicitia actúa aquí como personificación de la virtus femenina de la modestidad y castidad que la consorte trataba de irradiar (Burns, Great Women, 114).

50. Cuando Marciana murió y fue divinizada - primera diva de la dinastía- en 112, el título se otorgó entonces a su hija Matidia la Mayor - quien a su vez sería divinizada a su muerte en 119. De la misma manera, Sabina se convertiría en Augusta en 128, una vez que el princeps Adriano aceptó el paralelo de pater patriae; tras su óbito en 138 se convertiría en Diva Augusta Sabina (Burns, Great Women, 111, 115; Hidalgo de la Vega, Las emperatrices, 114-115; $c f$. Syme, Tacitus, 223).

51. Hidalgo de la Vega, Las emperatrices, 105-106.

52. GriffIN, «Nerva to Hadrian», 133; BurNS, Great Women, 116-117; cf. SHA Hadr. 2.10.

53. GRIFFIN, «Nerva to Hadrian», 134; Burns, Great Women, 117.

54. Rudolf Haensch: «Von Poppaea zu Pulcheria. Das Bemühen um Göttlichen Beistand bei der Geburt eines Kaiserlichen nachfolgers», Acta Philologica Fennica, 47, 2013, 131. Sobre la continuidad dinástica y la herencia del poder económico (e.g. figlinae Caepionianae): Hidalgo de la VEgA, Las emperatrices, 121-122; cf. SHA Ant Pius 7.9. 
con el futuro princeps Marco Aurelio. ${ }^{55}$ Por lo demás, su recuerdo se mantuvo siempre vivo gracias a los excelsos y múltiples honores que recibió. ${ }^{56} \mathrm{Con}$ todo, finalmente se construyó un modelo ideal de familia romana -alrededor de la pietas y la concordia - como virtus de la Domus divina. ${ }^{57}$

En lo concerniente a Faustina la Menor, al día siguiente del nacimiento de su primer vástago -147-, el senado -a instancias de Antonino Pío- le concedió el título de Augusta. ${ }^{58}$ El hecho de que se le otorgue precisamente en este momento resulta muy significativo, y es que Marco Aurelio tan solo recibió el título de Augustus en el momento de su acceso a la púrpura. Por primera vez «bekam also eine Frau vor ihrem Mann dieses älteste und prestigeträchtigste aller Cognomina eines Herrschers über das Imperium Romanum». ${ }^{59}$ Resulta preciso aclarar que no se trataba, como se ha sugerido, ${ }^{60}$ de poner a la mujer por encima del hombre, sino de realzar a la madre para dignificar así al sucesor engendrado. De esta forma observamos su uso como instrumento legitimador de la sucesión. Otorgaba la estabilidad necesaria al sistema al garantizar, el hijo biológico, que no hubiera lugar a peleas para convertirse en el hijo adoptivo, y evitando así que los altos mandos militares con disponibilidad de tropas lucharan entre ellos, tras haber conseguido proclamaciones locales, con vistas al reconocimiento final por parte del senado como legítimos emperadores. En dicha dispensa hemos de tener en cuenta asimismo la ausencia de una Augusta en vida en esos momentos después de la reciente muerte de Faustina la Mayor.

Faustina la Menor y Marco Antonio se mostraron como «prototipo de la armonía marital romana ${ }^{61}$ y así fue utilizado en la iconografía imperial dinástica. Si bien no dejan de haber testimonios, herederos de una tradición difamadora hacia su figura, que incluso llegan a involucrarla en conspiraciones por el poder. ${ }^{62}$

55. Anthony Birley: Marcus Aurelius. A Biography, Batsford, Londres, 1987 (1. a ed. 1966), 53.

56. E. g. estatua de oro: SHA Ant. Pius 6.8-9; institución alimentaria benéfica: SHA Ant. Pius 8.1-2, continuada después: Marc. 26.6; CIL VI, 10222; RE 1.2: 2314; BuRns, Great Women, 166. Por otro lado, contamos con las acusaciones de nimiam libertatem et vivendi facilitatem que lanza la siempre ofensiva hacia las damas imperiales Historia Augusta (Ant. Pius 3.7-8; cf. respecto su hija: SHA Marc. 19.11), no en vano, de dudosa credibilidad. Peter Weiss: «Die Vorbildliche Kaiserehe. Zwei Senatsbeschlüsse beim Tod der älteren und der jüngeren Faustina, neue Paradigmen und die Herausbildung des 'Antoninischen' Prinzipats», Chiron, 38, 2008, 39 la compara con Livia, la cual «sogar als genetrix orbis und mater patriae bezeichnet worden war und für die der Ehrentitel mater patriae ernsthaft erwogen wurde»; BuRNS, Great Women, 141 la define, con tintes eminentemente literarios más que históricos, como «the eternal empress».

57. WEISS, «Die Vorbildliche», 37-44.

58. RE 1.2: 2314; SHA Marc. 6.6.

59. HaENSCH, «Von Poppaea», 137.

60. Hidalgo de la Vega, Las emperatrices, 123; $c f$. Burns, Great Women, 157.

61. Hidalgo de la Vega, Las emperatrices, 124, cf. M. Aur. Med. 1.17.8.

62. Sobre el levantamiento de Avidio Casio: ShA Avid. Cass. 9.11, 10.5, 11.1, 11.3-8; Dio Cass. 72.22.3, 73.23.2-4, cf. 72.29.1; Birley, Marcus Aurelius, 184-189 «a highly puzzling episode»; Burns, Great Women, 164. 
Hidalgo de la Vega sigue un dudoso pasaje de la Historia Augusta $^{63}$ en el que Marco Aurelio -en estilo directo- argumenta contra las propuestas de divorcio diciendo que le debía el imperium a su esposa, porque esta se lo había transmitido como dote. Lo propone así la autora como ejemplo del papel legitimador de las mujeres de esta dinastía. De ninguna manera se puede atribuir un valor institucional a esa noticia, que habría que entender como un comentario mordaz. Lo que había convertido a Marco Aurelio en el futuro princeps eran, como sabemos, los poderes de la tribunicia potestas y el imperium concedidos por el senado a propuesta de su predecesor, y no un matrimonio con Faustina, respecto a la cual tan solo había continuado Antonino Pío la política matrimonial que se venía manteniendo por estas nuevas familias que estaban alcanzando el más alto grado social en Roma.

\section{LA DINASTÍA SEVERA}

El primer elemento por analizar es la relación entre Julia Domna y el prefecto del pretorio Plautiano, quien alcanzó altas cotas de poder en la corte severiana entre 199 y $205 .{ }^{64}$ Un hecho que haría disminuir la influencia de Domna en la misma, la cual vería a su primogénito Caracalla casado con la hija de aquel e incluso su pudicitia puesta en duda. ${ }^{65}$ Sin embargo, en ningún caso nos debe conducir a definir como «política» dicha rivalidad entre ambos, sino más bien de «caracteres dinástico-sucesorios» en vistas a la posible descendencia de Caracalla y Plautilla -ahora también Augusta-, a consecuencia de la cual Domna podría haber temido por la sucesión de sus hijos. ${ }^{66}$ Finalmente, una conjura de Plautiano sería descubierta y su promotor ejecutado ipso facto. A pesar de lo que el odio de Domna hacia el prefecto nos pudiera llevar a conjeturar, no hay evidencia alguna de su participación o planificación, ni de que ni siquiera tuviera constancia de lo que iba a ocurrir. ${ }^{67}$

Una de las consecuencias de la coyuntura con Plautiano fue el retiro de Domna al estudio de la filosofía creando a su alrededor un círculo - $v ́ \kappa \lambda o \varsigma-$ de intelectuales. Se convirtió así en la primera mujer entre las damas imperiales en interesarse por la erudición filosófica; antes tan solo había estudiado

63. Hidalgo De la VegA, Las emperatrices, 127, 180-181; SHA Marc. 19.8-9: «Si uxorem dimittimus, reddamus et dotem Dos autem quid habebatur [nisi] imperium, quod ille ab socero volente Hadriano adoptatus acceperat?».

64. Cf. Hdn 3.10.6; Cass. Dio 75.14.1-16.5, 75.15.2 ${ }^{\mathrm{a}}$; CIL VI, 225-226; BARbara Levick: Julia Domna: Syrian Empress, Routledge, Londres, 2007, 74; Birley, Marcus Aurelius, 235 n. ${ }^{\circ} 1$.

65. Cass. Dio 75.15.6; Burns, Great Women, 189.

66. Se acepta la opinión de que no tuvieron hijos, ya Dión (76.2.5) y Herodiano (3.10.8) informan de las negativas de Caracalla a tener relaciones con ella (Levick, Julia Domna, 75, 78; Birley, Marcus Aurelius, 232 n. $\left.^{\circ} 1\right)$.

67. Cf. Cass. Dio 75.15.6; 76.4.4; 78.24.1; Levick, Julia Domna, 80. 
retórica Cornelia, madre de los Graco. ${ }^{68}$ No se duda de la existencia de un grupo de naturaleza más bien informal y de asistencia flexible, sí en cambio de otorgarle un carácter eminentemente político. ${ }^{69}$

Sabemos que Julia Domna ejerció labores de secretaria ab epistulis Graecis et Latinis -no el puesto en sí mismo- durante el reinado de su hijo Caracalla, a quien encontramos en distintas ocasiones siendo aconsejado por aquella. ${ }^{70}$ Ello no puede conducirnos a la conclusión de su pertenencia al consilium principis ni de su participación en la elaboración en la Constitutio Antoniniana de 212 (Cass. Dio 78.9.5). La idea de que la plena dedicación de Caracalla a los asuntos bélicos dejaría vía libre para que Domna desarrollara una supuesta labor jurídica que conduciría a dicha promulgación ${ }^{71}$ «rest on no foundations». ${ }^{72}$

En esta misma línea, otro asunto de interés es la naturaleza del senaculum mulieris que nos dice la Historia Augusta (sHA Heliogab. 4.2-3) que creara Soemias en el antiguo lugar de reunión de las matronas -conventus matronarum- del Quirinal al comienzo del reinado de su hijo Heliogábalo. En apariencia, podríamos pensar que este "pseudo-Senate» ${ }^{73}$ presidido por Soemias no es sino otra de las extravagancias del emperador sirio, si no fuera porque es la imaginativa Historia Augusta la única fuente que nos informa de este suceso. Dión, con más crédito, ${ }^{74}$ sí que menciona la presencia de las damas imperiales en el senado, concretamente en 221 cuando Heliogábalo adopta a su primo Alejandro Severo. ${ }^{75}$ Hecho que tal vez influyera en una Historia Augusta inclinada a cada momento a la inventiva para utilizarlo como otro mero instrumento más de oprobio. ${ }^{76}$

Por último, en cuanto a la titulatura oficial que ostentaron las mujeres de la dinastía Severa, hemos de subrayar a Julia Domna pues sobrepasó a toda consorte imperial en número y variedad de títulos, honores que no en pocas ocasiones han provocado el debate en torno a su relación con el poder

68. Philostr. VS 2.622-623; Philostr. VA 1.3; Philostr. Ep. 73; Cass. Dio (75(76).15.6-7), posible testigo de los hechos (Fergus Millar: A Study of Cassius Dio. Oxford University Press, Oxford, 1999, 19). Cf. Birley, Marcus Aurelius, 241; Levick, Julia Domna, 117; Hemerlijk, Matrona Docta, 95; RE 10.1, 932.

69. Burns, Great Women, 189; Levick, Julia Domna, 112-113 n. 37, 114; HeMerliJK, Matrona Docta, 122; Hidalgo de la Vega, Las emperatrices, 150.

70. Cass. Dio 77(78).10.4, 18.1 ss.; $c f$. Cass. Dio 57.12.2 donde informa del mayor rol de Livia tras la muerte de Augusto, ocupándose incluso de escribir y recibir las cartas oficiales ( $c f$. Tac. Ann. 2.42.1; Suet. Claud. 4), si bien no corroborado con ninguna prueba y, lo que resulta más interesante, posiblemente influenciado por la conducta de Julia Domna en su propio tiempo.

71. Paloma Aguado: Julia Domna: la emperatriz romana, Aldebarán, Cuenca, 2010, 56.

72. Levick, Julia Domna, 97. El motivo fundamental de una reforma que convertía en ciudadano romano a todo habitante libre del Imperio no sería otro sino el económico, $i$. e. incrementar los ingresos devengados de las herencias (Cass. Dio 77.9.2-5; Millar, A Study, 153).

73. LeVICK, Julia Domna, 150 .

74. Millar, A Study, 168.

75. Cass. Dio 79.17.2; $c f$. SHa Heliogab. 12.3, 15.6. El único precedente que tenemos de la presencia de una mujer en el senado es que Agripina la Menor, quien, según nos cuenta Tácito (Ann. 13.5.2), escuchó in situ una sesión del senado, si bien tuvo lugar en palacio y lo hizo detrás de una cortina.

76. Cf. las burlas en SHA Heliogab. 4.4. 
político que les concedían. ${ }^{77}$ Conviene aclarar el título de Mater Castrorum y el de Mater senatus et patriae. El primero -ya ostentado por Faustina la Menor en similares circunstancias- lo obtuvo en 195 una vez que Niger resultó derrotado en la decisiva batalla de Issos e iría en consonancia con la subsiguiente salutación como imperator de Severo. Este pretendería consolidar el aspecto dinástico de su recién iniciado reinado y su perdurabilidad basada en la solidez militar y en la asociación sanguínea a los celebrados Antoninos. ${ }^{78}$ Respecto al segundo, Mater senatus supone una novedad formal, si bien existe el Pater senatus con el que fuera ya saludado Claudio (Tac. Ann. 11.25.7) y que fue acuñado por Cómodo en monedas de finales de su reinado; Mater patriae, por su parte, realiza ese cambio de género respecto del consolidado Pater patriae que presentaban los emperadores en su titulatura. Ambos, en definitiva, funcionarían en paralelo con su contrapartida en masculino a modo de afianzamiento dinástico de la consorte imperial de turno. ${ }^{79}$

\section{CONCLUSiones}

El poder político en el Principado viene definido únicamente por el imperium maius et infinitum y la tribunicia potestas. Poderes investidos única y directamente por votación del senado romano, por más que se tratara de algo formal, ya que lo verdaderamente importante era controlar al Ejército. A estos se suma el pontificado máximo como máxima autoridad religiosa y todo ello rodeado del aura de la auctoritas. Pues bien, queda claro que ninguna mujer de la casa de los Césares llegó a ejercer ni de iure ni de facto ninguno de estos poderes políticos institucionales. Algo que, en ocasiones, en el abuso de cierta historiografía de tonos más feministas, se pone en cuestión.

La concesión de la sacrosanctitas tribunicia no supuso en ningún caso el desempeño del tribunado de la plebe ni sus atribuciones políticas. Se trató más bien de una forma honorífica de protección contra posibles ataques verbales hacia la persona, y hay que entenderlo exclusivamente en el contexto político del ocaso del Segundo Triunvirato. El tópico que atribuye a Livia todo tipo de maquinaciones en torno al uso del veneno para liquidar a los sucesivos candidatos a relevar a Augusto parece que no es sino una parcialidad de los autores antiguos -sobre todo de Tácito- convertida en paradigma y asumido sin mayor crítica. Por su parte, tanto la adopción de Livia en la familia Julia

77. Iulia Pia Felix Augusta Mater Augusti Nostri et Castrorum et Senatus et Patriae (RE 10.1: 936-939). Los títulos de Pia Felix, otorgados por Caracalla a Domna, guardan relación con las virtudes de la pietas en referencia a la devoción-y la felicitas -a la buen fortuna en general- respectivamente. Algo común entre los emperadores pero que supuso una novedad para el caso de las mujeres.

78. Cf. Sha Sev. 10.6; Hdn 3.10.5; Birley, Marcus Aurelius, 182, 184, 254; Levick, Julia Domna, 40, 42, 56; Lo CASCIO: «The emperor and his administration. The age of the Severans», en Bowman, A.K.; Garnsey, P.; Cameron, A. (eds.): The Cambridge Ancient History 12, Cambridge University Press, Cambridge, 2009, 137-138; CIL VI, 154; VIII, 26498.

79. LeviCK, Julia Domna, 94; CIL VI, 40646 = AE 1983, 28; CIL III, 419. 
como su tardía divinización no dejan de mostrar los intentos por utilizar su figura a modo de consolidación dinástica del nuevo régimen.

La fundación de Colonia Claudia Ara Agrippinensium debemos comprenderla siempre desde la idea de que, aun apoyándose en una proposición de su esposa Agripina ya en mayor o menor medida, se trató ulteriormente de una medida que seguía una política ya previamente marcada por el princeps Claudio, de quien emanaría la orden de manera inequívoca, pues no había otra persona con capacidad jurídica para ello. Mediante los Commentarii Agrippinae, que marcan un precedente extraordinario en la prosa latina, Agripina buscaría unos fines asimismo políticos para arrogarse de manera indirecta una legitimidad dinástico-jurídica de la que como mujer carecía.

Con la dinastía Antonina, apareció un nuevo modelo de consorte imperial con un carácter menos independiente que las Julio-Claudias, si bien en un periodo más llano y con un régimen consolidado que permitió el renacimiento de una nueva edad de oro. El prestigio de los reinados de sus esposos y su cumplimiento con las virtutes que en ellas se esperaba provocaron que generaran el perfecto ideal de familia romana, el cual se irradió a la sociedad a través de la iconografía imperial.

Finalmente, en cuanto a la dinastía Severa, conviene aclarar que sus damas imperiales en absoluto actuaron de manera autónoma con respecto a las decisiones políticas adoptadas. Hemos de observarlas más bien desde el punto de vista de la problemática sucesoria, comenzando por la cuestión entre el prefecto Plautiano y Domna y que concluiría tras la actuación de Caracalla, seguramente influido por su madre. El conocimiento de la existencia de un $\kappa v ́ \kappa \lambda o \varsigma$ de eruditos alrededor de Domna nos indica el grado de inteligencia que ostentaba la consorte y confirma la evolución de la autonomía femenina en lo concerniente a sus aficiones personales, aun superando los prejuicios imperantes respecto a su dedicación a estudios retóricos. Pero queda desechado todo posible posicionamiento político del grupo. Por su parte, el llamado senaculum mulierum no debe confundirnos. El tamiz metodológico de la crítica de fuentes cerca el concepto y lo limita a un lugar de reunión de la alta sociedad femenina sin ningún carácter vinculante en asuntos del Estado.

En perspectiva, la participación en algunos documentos oficiales de las consortes imperiales ha sido esgrimida por algunos como indicativo de su institucionalización en la Domus imperial. Nada más lejos de la realidad, simplemente se dedicaban a organizar los asuntos intra cubiculum, pues con el cambio de régimen las mujeres de los principes habían pasado a ampliar su rango de acción en una economía doméstica más compleja que la de una persona privada.

Así, el hecho de que las damas imperiales mantuvieran una constante comunicación con su esposo, hijo o nieto en posesión de la púrpura no debe sorprendernos. Podría, pues, considerarse natural que le consultara o simplemente contara los asuntos de su quehacer político. Que se vieran influenciados por sus propuestas es algo que quedaría en palacio -o en el 
Praetorium, dada la asiduidad de su presencia en los castra- pero que, en el caso de que se produjera, tampoco podríamos hablar de ellas como figura política.

Las fuentes confirman claramente el papel de legitimadoras dinásticas de las consortes imperiales, aunque resulta evidente que no desempeñaron poderes institucionales, sino que su forma de protagonismo a nivel estatal se encuadra en su rol de género - a través del título de Augusta y la continua mención como Mater- como productoras del deseado heredero que facilitara la continuidad y la estabilidad dinástica. Esto es, que se evitaran las proclamaciones locales y subsiguientes perturbaciones en provincias con disponibilidad de tropas y personajes influyentes. Por esta razón, a la hora de calificar sus actividades administrativas hemos de ser cautos y evitar a toda costa hablar de «administering the Empire (...) coregent and queen mother ${ }^{80}$ y no caer, como han hecho algunos ${ }^{81}$ en la idea de que una mujer podría presidir el consilium principis e incluso promulgar edictos como la Constitutio Antoniniana.

Para terminar, y siguiendo esta misma línea, la significación y simbolismo de la titulatura y onomástica de las mujeres de la Domus divina no se correspondía con aquel que conllevaba el de los principes. Y es que recordemos, sin ir más lejos, que las palabras para referirse al emperador que utilizaban los romanos eran las de imperator -como general en jefe de todo el ejército- así como princeps -en el ámbito civil, primus inter pares, primer ciudadano-, y Caesar. Hemos de percatarnos, en definitiva, que la lengua latina no cuenta con términos femeninos para referirse a una supuesta «emperatriz» que pudiera ejercer de copartícipe en el poder más allá del de Augusta que, como hemos visto, sus connotaciones se alejan de dicho significado - destacan más bien sus vínculos religiosos y su relación con el verbo augeo y con auctoritas-. Debemos ignorar, por tanto, toda acepción que suponga su adherencia a funciones ejercidas por los hombres, esto es, militares y políticas. Y es que el título de Augustus funciona como un cognomen que pone de manifiesto la continuidad dinástica del Principado. Todos los emperadores, a partir de Vespasiano, lo llevan, con lo que va de la mano con el reconocimiento, por parte del senado, del nuevo princeps. Debemos, por añadidura, hacer mención de la constante aparición de la palabra Mater. Su significado se encuentra muy cercano al de Augusta. Tiene connotaciones sacrales con esa aura divina que muchas veces lleva consigo la maternidad. Los emperadores procuraron asociar a algunas mujeres de la familia imperial dicha característica y así ponerlas en relación con la figura institucional del Estado. Eran descritas como madres, en el sentido de protectoras, del Imperio. Un sentido simbólico que se convierte en literal cuando eran descritas en las inscripciones como madres del sucesor o del propio emperador. Se trata de legitimadores conceptuales ante el pueblo.

80. LeVICK, Julia Domna, 96.

81. Godfrey Turton: The Syrian Princesses: the women who ruled Rome A. D. 193-235, Cassell, Londres, 1974, 110, cf. 2, 111, 167-169. 
En suma, fueron la legitimación dinástica y la participación en el culto imperial lo que sustanció el rol femenino de las consortes imperiales.

En la historiografía antigua observamos la dualidad, por un lado, del ensalzamiento de los roles femeninos asociados a emperadores considerados como virtuosos-los «emperadores buenos»-, en tiempos áureos y de armonía, frente, por otro lado, al vilipendio que llevan a cabo contra toda intromisión de aquellos en la esfera de actuación masculina, y suelen relacionarlos a emperadores débiles -«malos»- y a épocas de mayor desconcierto del régimen político. Con todo, hemos de entender las deformaciones de los comportamientos de algunas mujeres de la Domus imperatoria en las construcciones históricas desarrolladas por historiadores clásicos, como parte de un género literario histórico que en la Antigüedad se dirigía más al gusto de los lectores de la época que a la búsqueda de la veracidad histórica. 